This PDF is a selection from an out-of-print volume from the National Bureau of Economic Research

Volume Title: Tax Policy and the Economy, Volume 12

Volume Author/Editor: James M. Poterba, editor

Volume Publisher: MIT Press

Volume URL: http://www.nber.org/books/pote98-1

Publication Date: January 1998

Chapter Title: Taxation by Telecommunications Regulation

Chapter Author: Jerry Hausman

Chapter URL: http://www.nber.org/chapters/c10912

Chapter pages in book: (p. 29 - 48) 


\title{
TAXATION BY TELECOMMUNICATIONS REGULATION
}

\author{
Jerry Hausman \\ MIT and NBER
}

\section{EXECUTIVE SUMMARY}

Telecommunications has become an increasingly important area of attention by policymakers as new services such as cellular telephone and Internet services become increasingly important to businesses and consumers. Rapidly changing technology has led to these new services as well as the realization that market-based competition may replace much outdated regulation which has led to considerable consumer harm (e.g. Hausman, 1997). Congress passed the Telecommunications Act of 1996, the first major change in telecommunications legislation since 1934, in response to these changes.

What role does the field of public finance have in the analysis of telecommunications policy? Telecommunications regulation in the U.S. is replete with a system of subsidies and taxes, in part because of the dual system of regulation in which the federal government (FCC [Federal Communications Commission]) and each state has regulatory jurisdiction over local telephone companies. ${ }^{1}$ Public-finance analysis demonstrates how to

Susan Dynarski and Hyde Hsu provided research assistance. Jim Poterba and Tim Tardiff provided helpful comments.

1 Broadly speaking, the FCC has jurisdiction over interstate calls and about $25 \%$ of the capital base of local telephone companies, while state regulation does intrastate calls and the remaining $75 \%$ of the capital base. Numerous exceptions exist with respect to interstate versus intrastate calls, and some services have aspects of both interstate and intrastate calls. 
evaluate the costs and benefits of tax and subsidy systems. ${ }^{2}$ Indeed, it demonstrates how to measure the distortions to economic efficiency that tax and subsidy systems create. ${ }^{3}$ Furthermore, it has determined rules for optimal taxation that can be applied to telecommunications regulation. ${ }^{4}$

A potentially important application of public-finance analysis to telecommunications regulation is the financing by regulation of telephone companies' fixed and common costs. Because of significant economies of scale and scope, the first best prescription of setting price equal to marginal cost would require government subsidies or would lead to bankruptcy of local telephone companies. ${ }^{5}$ In the U.S., government subsidies have not been used, and regulators have set price in excess of marginal cost for some services to allow regulated telephone companies to cover their fixed and common costs and to provide a subsidy to basic residential service. Here Ramsey optimal tax theory would suggest how prices should exceed marginal costs to minimize the efficiency losses to the economy. ${ }^{6}$ Although Ramsey theory was devised for the purpose of raising revenue in just the situation that regulators face, it has found little acceptance in telephone regulation, perhaps for the reason that most of the tax burden would fall on local telephone service, which actually receives the highest subsidy of any telephone service.

Another potential application for public finance analysis in telecommunications regulation, and the main topic of my paper, is the marginal cost to the economy of the new Congressional legislation which leads to taxation of telecommunications services. Because of budgetary spending limits, Congress is increasingly unable to increase general taxes to pay for social programs. ${ }^{7}$ Thus, Congress increasingly funds social programs from taxes on specific sectors of the economy. In this paper I consider the Congressional legislation which established a program so that all schools and libraries in the U.S. will receive subsidized access to the Internet.

2 Some Washington lawyers might quibble about the use of "tax" here, since the FCC is only allowed to assess "fees," not taxes. However, public-finance economists know a tax when we see one.

${ }^{3}$ See e.g. Auerbach (1985).

${ }^{4}$ For optimal taxation analysis see e.g. Diamond and Mirrlees (1971), and for an application of Diamond-Mirrlees theory to telecommunications regulation see e.g. Hausman (1995).

${ }^{5}$ This point has long been recognized. See e.g. Kahn (1988).

${ }^{6}$ For recent recommendations using Ramsey theory in the context of price-cap regulation see e.g. Laffont and Tirole (1996).

7 The 1990 Budget Enforcement Act includes a pay-as-you-go restriction on tax changes and changes in entitlement programs other than Social Security. Poterba (1997) discusses the budget experience under this act. 
The cost of the program is currently estimated to be $\$ 2.25$ billion per year. ${ }^{8}$ Rather than increasing general taxes to fund this program, Congress passed legislation that directed all users of interstate telephone service to pay for the program. Congress left it to the FCC to decide how to tax users of telephone services to pay for this new subsidy. ${ }^{9}$

In this paper I calculate the efficiency cost to the economy of the increased taxation of interstate telephone services to fund the Internetaccess discounts to schools and libraries. ${ }^{10} \mathrm{I}$ do not attempt to measure the benefits, but for reasoned policy decisions the cost estimates are useful. ${ }^{11}$ I estimate the cost to the economy of raising the $\$ 2.25$ billion per year to be at least $\$ 2.36$ billion (in addition to the $\$ 2.25$ billion of tax revenue), so that the efficiency loss to the economy for every $\$ 1$ raised to pay for the Internet-access discounts is an additional $\$ 1.05$ to $\$ 1.25$ beyond the money raised for the Internet discounts. ${ }^{12}$ This cost to the economy is extraordinarily high compared to other taxes used by the federal government to raise revenues. There are three reasons for the high cost to the economy of this increased tax on interstate long distance

${ }^{8}$ This subsidy is only a small part of a much larger framework of universal service subsidies. Congress passed the legislation establishing the subsidies, but the FCC determined the \$2.25-billion-per-year amount.

${ }^{9}$ Supposedly Gladstone, while Chancellor of the Exchequer, asked Michael Faraday about the usefulness of electricity. Faraday responded, "Why Sir, there is every possibility that you will soon be able to tax it."

${ }_{10}$ Thus, this paper demonstrates how to answer the question raised by Posner (1971) of the cost of subsidy programs arising from regulation.

11 The question of benefits is worthy of further study. For instance, all public schools (and some private schools) and all public libraries receive a subsidy for their purchase of Internet access. While the subsidy scheme is progressive, over 97 percent of schools receive at least a 40 percent discount and over 67 percent of schools receive at least a 50 percent discount. One might question why communities such as Weston, MA, with a 1990 median family income of $\$ 95,134$, and Hillsborough, CA, with a 1990 median family income of $\$ 123,625$, require a subsidy, especially given the high proportion of high-technologyrelated job holders in both towns. Given the likely outcome that these towns will not change their purchase behavior even with the subsidy, the subsidy represents a pure transfer from long-distance users to taxpayers of these communities.

12 This estimate is an approximation, because the funds will be raised from all interstate telecommunications services, e.g. cellular telephone, not just regular long distance. The FCC estimates that about 1.5 percent of end-user wireless revenues will be used in the tax. Thus, I base my estimate of the efficiency loss to the economy on the assumption that $\$ 1.89$ billion will be raised through a tax on long-distance calls. I do not include the additional efficiency loss to the economy from the tax on wireless services. Given my estimate of the cellular demand-price elasticity (Hausman, 1997), the tax on wireless will also lead to a significant additional loss in economic efficiency to the economy. Including the efficiency loss from the tax on wireless services would increase my estimate of the efficiency loss from $\$ 2.36$ billion to $\$ 2.53$ billion. Also, taking account of general equilibrium price effects would lead to a further increase in my estimates. 
services: (1) the price elasticity of long-distance services is relatively high, (2) the taxation of interstate long-distance services is already quite high, and (3) the price-to-marginal-cost ratio of long-distance services is high. Thus, the FCC's choice of a tax instrument to finance the Internet discounts imposed extremely high efficiency costs on the U.S. economy.

Next, I propose an alternative method by which the FCC could have raised the revenue for the Internet discounts, which would have a nearzero cost to the economy, beyond the revenues raised. Econometric research has led to wide agreement on the relative size of telephoneservice price elasticities, and the FCC could have chosen to increase other taxes, already in place, which would have led to much lower costs to the economy of funding the Internet discounts. Indeed, economic theory and public finance analysis establish the goal of using taxes which minimize the cost to the economy of raising government revenue. The FCC, to the contrary, chose the taxation method applied to interstate telephone service which likely maximizes the cost to the economy of raising the revenue to provide the Internet discounts.

Hopefully, the FCC will begin to take heed of economic analysis in the future as it continues to modify the tax and subsidy system for telecommunications. The Telecommunications Act of 1996 calls for further modifications to regulation in the future. Telecommunications regulation at the federal level has always recognized the "public interest standard" as one of the main bases for regulation. The public interest standard should recognize economic efficiency as one of its primary goals. Economic efficiency implies not assessing unnecessary costs on U.S. consumers and firms. The FCC's current policies are costing the U.S. economy billions or tens of billions of dollars per year. The geal of the Telecommunications Act of 1996 was to decrease these regulatory costs to the U.S., not to increase them.

\section{REGULATION OF TELECOMMUNICATIONS IN THE U.S.}

Regulation of telecommunications in the U.S. is unique among all countries in that two levels of government regulate telephone service: the federal government through the FCC and each of 51 state (including the District of Columbia) regulatory commissions. In broad principle the FCC is in charge of interstate telecommunications while the state regulatory commissions are in charge of intrastate telecommunications. While the FCC has periodically attempted "power grabs" to attain more control over regulation, these activities have been resisted by the state commissions, 
which have been upheld by the courts in two notable decisions, the Louisiana decision (1986) and recently in the interconnection decision by the Eighth Circuit Court of Appeals in July $1997 .{ }^{13}$ Both times, the Appeals Courts have narrowly circumscribed the ability of the FCC to intervene in intrastate telecommunications regulation.

However, as most users of a telephone realize, the same telephone wire which connects a residence to the local central office switch, the switch itself, and the fiber-optic cable which connects the switch to other switches carry both intrastate calls and interstate calls. Thus, no natural boundary exists to demarcate spheres of regulation. In an earlier era of telephone regulation (about 15 years ago), when cost of service, i.e. rate of return regulation, was used, the rate was arbitrarily separated into an intrastate portion and an interstate portion, primarily on the number of calls of each type. Thus the separations system was put into place, and over time it has achieved an increasingly complicated level of detail that only a regulatory accountant could love and perhaps no living person can understand completely. The separations system, if it ever made sense, has no basis in economic reality today, since rate-base regulation is no longer used by the FCC and has disappeared from use by a majority of the states.

The end result of the separations system is that the FCC interstate regulation is responsible for about 25 percent of the local exchange companies' assets, and state regulators are responsible for the other 75 percent. Under rate-of-return regulation, the regulated telephone companies' profits in each regulatory regime were meant to be large enough to allow them to earn their regulated cost of capital on these regulatory-determined rate bases.

Prior to the breakup of AT\&T in 1984, local residential service was cross-subsidized by long-distance service through intra-company transfers, the result of an earlier agreement with regulators and the Ozark Plan of $1971 .{ }^{14}$ After the AT\&T divestiture, an explicit subsidy flow had to be established to continue the cross subsidy of local residential service. ${ }^{15}$ The FCC established a per-minute-of-use access fee that longdistance companies were required to pay local telephone companies for

${ }^{13}$ Louisiana Pub. Serv. Comm'n v. FCC, 476 U.S. 355 (1986) and Iowa Utilities Board et al. v. FCC, Eighth Circuit, July 18, 1997.

14 In its antitrust suit against AT\&T, the Department of Justice claimed that AT\&T used its local access revenues to cross-subsidize its long-distance competition with $\mathrm{MCI}$. This theory was incorrect: the cross subsidy flowed in the opposite direction, as subsequent events demonstrated conclusively. Indeed, the Department of Justice recognized its mistake in a court filing in 1987.

15 By the term cross subsidy, I mean setting price less than long-run incremental cost. 
the use of their networks to originate and terminate long-distance calls. ${ }^{16}$ The access fees were initially set quite high, about 17.3 cents per minute for both origination and termination. The access fees had the same effect as a tax on long-distance calls, because the access fee is paid for the subsidy on local residential service as well as paying for some of the fixed and common costs of the local exchange companies which were included in the FCC's 25 percent share of the local exchange companies' rate bases that the FCC held charge over. ${ }^{17}$

These access charges were not a very economically efficient set of taxes, since studies funded by AT\&T Bell Laboratories had consistently demonstrated an interstate long-distance elasticity of about $-0.7 .{ }^{18}$ Furthermore, policymakers did not seriously analyze the fundamental question of whether every residential telephone customer should receive a cross subsidy, no matter what the income of the customer. Cross subsidies of local telephone service were discussed under the rubric of "universal service" which was contained in the Telecommunications Act of 1934. However, by 1984 telephone penetration in the U.S. was about 91.5 percent with additional targeted subsidies in place for low-income customers. Current telephone penetration is about 93.9 percent. Econometric studies which I conducted did not show any significant "network effects" at this level of penetration; I am unaware of any econometric studies which did show a significant network externality. ${ }^{19}$ Thus, the replacement of a universal cross subsidy with targeted subsidies (e.g. telephone stamps) would have been more economically efficient than access charges for long distance, but such a rational policy was never seriously considered by policymakers.

16 All the taxes on long distance which I discuss were established by the FCC, although Congress does exercise oversight on the FCC.

17 Many other cross subsidies and distortions arise from state regulation, such as the subsidy to rural telephone subscribers, who are generally significantly higher cost to serve, but who pay the same rates as urban customers when served by a common local exchange provider.

18 See e.g. Taylor (1994). These estimated elasticities were based on times-series data, which led to very precise estimation given the significant decrease in long-distance prices which occurred in the 1970s. More recent estimates also lead to very precise results. Thus, a one-standard-deviation change in the elasticity estimate would not affect the results of my calculations by a significant amount. A quite interesting finding is that the price elasticity for long-distance service did not change and remained at much the same value up through the 1990s, as I discuss later. Thus, the onset of long-distance competition did not affect the price elasticity; nor did competition significantly affect the position of the demand curve over time (no outward shift of the demand curves due to competition has been estimated).

19 Taylor (1994, pp. 236-238) summarized the size of the estimated network externality effects. He concludes that they are quite small. 
In 1984 the FCC adopted a framework which did allow for a significant decrease in long-distance access charges. It adopted a subscriber line charge (SLC), which reached $\$ 3.50$ per line per month for residential households and $\$ 6.00$ per line per month for businesses. Access rates for long distance decreased from about 17 cents per minute to about 9.5 cents per minute, primarily as a result of the advent of the SLC. The FCC considered a higher SLC which would have decreased long-distance access rates even more, but Washington lobbying groups such as the Consumer Federation of America (CFA) made apocalyptic forecasts of 6 million households stopping their telephone service, which would have decreased telephone penetration below 85 percent. As with much of the policy debate over telephone regulation during the past 20 years, the CFA's forecasts were based on little real economics and proved to be vastly inaccurate. Indeed, telephone penetration increased because of the SLC and lower access prices, as demonstrated by Hausman, Tardiff, and Belinfante (1993).

The SLC was quite unlikely to lead to large decreases in telephone penetration, since an increase in the SLC leads directly to lower longdistance prices, and telephone subscribers needed local service to make long-distance calls. Available data at that time demonstrated that lowincome households made numerous long-distance calls; indeed, about half of their monthly telephone bills was in long-distance calls. Thus, economic analysis led to the conclusion that consumers buy telephone service for both local calls and long-distance calls, and because an increase in the SLC would be more than counteracted by the decrease in long-distance call prices (because of the relatively high long-distance price elasticity), the monthly bill of the large majority of residential customers would decrease when the number of long-distance calls was held constant. Economic-efficiency calculations demonstrated that consumers would be made better off by billions of dollars per year if the SLC were further increased and the long-distance charges decreased. Nevertheless, the FCC refused to allow the SLC to increase further, even at the rate of inflation.

\section{STUDIES OF TELEPHONE DEMAND: THE RELEVANT ELASTICITY PARAMETERS}

To determine the economically efficient method of taxation within telecommunications regulation, given that subsidies are unlikely to disappear any time soon, estimates of certain demand elasticities are needed. The first elasticity that I discuss is the demand elasticity for local exchange 
access. Throughout the U.S., with the exception of New York City, most residential customers buy unlimited use local calling, so-called flat rate local service. ${ }^{20}$ This service also allows the consumer to make longdistance calls, typically through a pre-subscribed long-distance carrier such as AT\&T or MCI. The imposition of the SLC as well as other local rate increases in the 1980s, together with the decrease in long-distance prices (caused mainly by the decrease in access charges), allows relatively precise estimation of the demand for residential service. ${ }^{21}$

Hausman, Tardiff, and Belinfante (1993) modeled the demand for local access as a partially indirect utility function which recognized the demand for both local calls and long-distance calls. Their basic partially indirect utility function takes the form

$$
u=u(y, p, q, z, \epsilon)
$$

where $y$ is household income, $p$ is a vector of prices for basic exchange access which includes the one-time installation price and the monthly basic exchange price, $q$ is a vector of prices of usage for local service (whose price is often zero) and both intrastate and interstate long distance services, $z$ is a function of household characteristics, and $\epsilon$ is a random parameter which is independently distributed across households. Hausman, Tardiff, and Belinfante (1993) estimated the basic exchange-access discrete-choice equation where a household purchases telephone service if

$$
\tilde{u}_{1}=\tilde{u}\left(y-p_{1}-p_{2}, q, z, \epsilon\right) \geq \tilde{u}(y, z, \epsilon)=\tilde{u}_{2}
$$

where $\tilde{u}_{1}$ is the partially indirect utility function in which the basic access price has been subtracted from household income, and $\tilde{u}_{2}$ is the partially indirect utility function in which all consumption is of the composite (non-telephone) commodity. An important finding of equations (1) and (2) is that the discrete-choice equation should depend on the basic access price(s) and also the usage prices, including long-distance prices. The econometric specification is in marked contrast to almost all other previous specifications of basic access demand, which did not include long-distance prices. This specification, where the demand for local access depends on both the price of local access and the prices for long-

${ }^{20}$ In New York City, only measured-rate local service is offered by NYNEX (Bell Atlantic).

${ }^{21}$ Part of the increase in local access charges for residential service was caused by the high inflation rates of the 1970s. As usual, regulators took a number of years before recognizing the increased costs of the inflationary period. 
distance calls, has been incorporated in subsequent studies of basic access demand.

The study by Hausman, Tardiff, and Belinfante used panel data for the years 1984-1988 from a random sample of about 55,000 households. They estimated the elasticity with respect to the basic access price to be -0.005 , which is quite small, a 10 percent price increase leading to a 0.5 percent decrease in penetration (which is approximately 0.005 , given a penetration rate of about 0.93 ) The finding of a very small, but significantly nonzero, own price elasticity for residential basic access demand is consistent with prior studies, the best-known being the paper of Perl (1984), which was followed by studies such as those of Ericksson, Kaserman, and Mayo (1995) and Solvason (1997).

The very small price elasticity effect has led some regulators to resist raising basic access prices because of the negative effect on telephone penetration. However, concentration on only the own price effect could lead to incorrect conclusions. Hausman, Tardiff, and Belinfante (1993) estimated that the cross price elasticity of the demand for basic access service with respect to the price of intra-LATA toll service is -0.0086 and with respect to interstate toll service is -0.0055 , which demonstrates the complementary nature of basic access demand and local and longdistance telephone usage. Thus, an increase in basic access demand combined with a decrease in long-distance toll prices (via a decrease in long-distance access prices) could well lead to an increase in telephone penetration, rather than a decrease as has been assumed by many regulators. Hausman, Tardiff, and Belinfante concluded that the imposition of the SLC and the associated decrease in long-distance prices led to an increase in telephone penetration of about 450,000 households. Thus, the SLC had led to increased telephone penetration and increased economic efficiency, since the lower access fees led to lower distance prices, which led to a significant increase in long-distance calls.

The other important elasticity for an economic analysis of efficient telecommunications tax policy is the interstate long-distance price elasticity. Taylor (1994) had estimated this elasticity to be about -0.7 , based on 1970s data and subsequent studies based on data from the 1980s by Gatto et al. (1988), Taylor and Taylor (1993), and Taylor (1994), have continued to estimate very similar elasticities. ${ }^{22}$ Thus, the consensus elasticity estimates for interstate long distance calls are in the range of -0.65 to -0.75 . This finding of constant elasticity is quite interesting,

22 The elasticity for intrastate long-distance calls is significantly lower, but here I consider only interstate long-distance calls, since the FCC regulates only these calls through its long-distance access charges. 
given the real decrease in long-distance prices by about 50 percent over this period as well as the outward shift of the demand curve, mainly due to increased incomes, since the income elasticity of long-distance demand is about $1.0 .^{23}$

\section{ESTIMATION OF ECONOMIC-EFFICIENCY LOSSES}

Taxes (and subsidies) distort economic activity. Taxes increase prices and thus lead to lower demand. This lower demand has two adverse affects on economic efficiency, which is defined (approximately) as the sum of producer surplus and consumer surplus. To the extent that the industry is imperfectly competitive and price exceeds marginal cost to cover fixed costs, decreased demand reduces the amount of producer surplus, which is the product of quantity demanded times the difference between price and marginal cost. ${ }^{24}$ Decreased demand from higher prices also affects consumers adversely, since consumer surplus decreases. Thus, the change in economic efficiency from the imposition of a tax is given approximately by the formula

$$
\begin{aligned}
\Delta E & \approx\left[-\Delta q_{i}\left(p_{i}-m_{i}\right)-0.5 \Delta p_{i} \Delta q_{i}\right] \\
& \approx\left[\eta_{i} \frac{\Delta p_{i}}{p_{i}}\left(p_{i} q_{i}-m_{i} q_{i}\right)+0.5 \eta_{i}\left(\frac{\Delta p_{i}}{p_{i}}\right)^{2} p_{i} q_{i}\right]
\end{aligned}
$$

Where the first term is the change in producer surplus and the second term is the change in consumer surplus, after the amount raised by the tax is subtracted off. ${ }^{25}$ Figure 1 provides a graphical demonstration of this relationship. Equation (3) demonstrates that taxes which cause prices to increase create losses in economic efficiency, with the size of the efficiency loss depending on the price elasticity $\eta_{i}$, the magnitude of the price increase $\left(\Delta p_{i} / p_{i}\right)$, the revenue of the good or service being taxed $\left(p_{i} q_{i}\right)$, and the marginal cost of production $\left(m_{i}\right)$.

A more accurate method than equation (3) replaces its second term with a calculation of the exact deadweight loss to consumers based on the analysis of Hausman (1981a). Rather than using the Taylor expan-

${ }^{23}$ The CPI for interstate toll calls fell by approximately 25 percent from 1984 to 1994 , so that real prices fell by more than 50 percent.

${ }^{24}$ Even in a free-entry imperfectly competitive industry with constant marginal cost and zero (economic) profits, price will exceed marginal cost.

25 Thus, as discussed above, the possible distortions created by expenditure of the tax are not considered. All the quantities in the formulae are assume to be Hicksian compensated quantities. See Hausman (1981a) for computation of compensated quantities. 


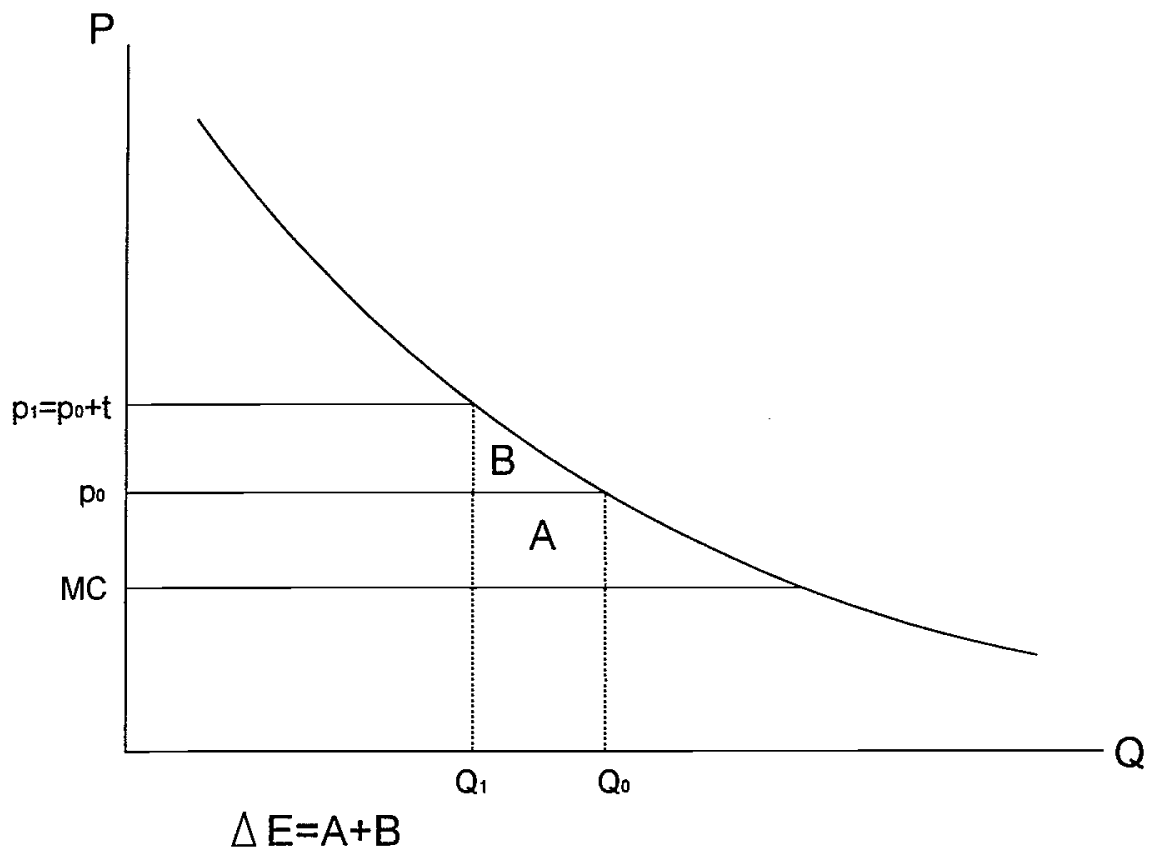

FIGURE 1. Graph of Equation (3)

sion, I use the expenditure function based on the log-linear demand curve to calculate the compensating variation from the increase in taxes:

$$
C V=\left(\frac{1-\delta}{1+\alpha} y^{-\delta}\left(p_{1} x_{1}-p_{0} x_{0}\right)+y^{1-\delta}\right)^{1 /(1-\delta)}-y
$$

where $\delta$ is the income elasticity (0.8) and $\alpha$ is the price elasticity. To calculate the deadweight loss to consumers, I subtract the compensated revenue raised $R^{*}$ from the compensating variation calculated in equation (4): $D W L=C V-R^{*}$. The DWL estimate replaces the second term in equation (3). Hausman (1981a) demonstrates that this exact calculation can be considerably more accurate than the approximation contained in equation (3).

\subsection{Estimation of the Efficiency Loss from Increased Long-} Distance Access Charges

Using equation (3), the long-distance elasticity estimate considered above, and the fact that the marginal cost of long distance is at most about 0.25 of the price while the long-distance access rate per minute is 
$\$ 0.0604$ per minute, I estimate that for the average revenue raised by the tax on long distance, ${ }^{26}$

$$
\Delta E=0.654 \times T R,
$$

where $T R$ is the tax revenue raised. This calculation follows from dividing through equation (3) by the access revenue raised, $t_{i} q_{i}$ (i.e. the tax revenue term $T R$ ) and using long-distance revenue and access revenue amounts collected by the FCC. The first term in equation (3) (after dividing by $T R$ ) is estimated to be 0.415 , and the second term is estimated to be 0.239 . Thus, the average efficiency loss to the economy for each $\$ 1$ raised through the access tax is $\$ 0.65$, which is quite high, as will be seen subsequently. Indeed, by changing the method by which the access-tax revenue is raised, this efficiency loss could be reduced to essentially zero; see Hausman (1995).

Using the exact approach based on Hausman (1981a) and equation (4), I calculate the average efficiency loss to the economy for each $\$ 1$ raised through the access tax to be $\$ 0.79$ instead of the $\$ 0.65$ which I estimated using the traditional approximation based on equation (3). Thus, I find that the exact calculation leads to a higher estimate of average efficiency loss than the approximate method based on a Taylor expansion.

Perhaps a more relevant calculation is the marginal efficiency loss to the economy, since the access tax is already in place, and the recent FCC action to fund the Internet subsidy to schools and libraries increased the tax (or at least caused it not to decrease as much as it would have). The formula for the marginal efficiency loss is computed by taking the marginal change in equation (3) with respect to the tax rate, $\partial \Delta E / \partial t_{i}$, and dividing by the marginal change in tax revenue with respect to the tax rate, $\partial \mathrm{TR} / \partial t_{i}$ :

$$
\frac{\partial \Delta E / \partial t_{i}}{\partial T R / \partial t_{i}} \approx \frac{\eta_{i} \frac{1-m_{i}}{p_{i}}+\eta_{i} \frac{t_{i}}{p_{i}}+\left(\eta_{i} \frac{t_{i} m_{i}}{p_{i}^{2}}-0.5 \eta \frac{t_{i}^{2}}{p_{i}^{2}}\right) \frac{\partial p_{i}}{\partial t_{i}}}{1-\eta_{i} \frac{t_{i}}{p_{i}} \frac{\partial p_{i}}{\partial t_{i}}} .
$$

${ }^{26}$ While the basis for the tax will be extended to intrastate revenues as well as interstate revenues, the FCC will still raise the money through the interstate long-distance access charges by including it as an exogenous cost change (" $z$ factor") in the telephone companies' $^{\prime}$ price cap formula which determines the interstate long-distance access rates. The FCC maintains two other tax programs to fund universal service, the "lifeline" and "linkup" programs, which lead to an additional monthly charge of $\$ 0.5371$ per access line. However, I do not consider the effect of these additional taxes in equation (5) or the subsequent calculations. Incorporating these additional taxes would increase the estimate of the efficiency loss to the economy. 
Using equation (5) together with the assumption that $\partial p_{i} / \partial t_{i}=1$ along with the fact that $t_{i} / p_{i}=0.403$, I estimate equation (6) to be 1.249 .27 Thus, the marginal efficiency loss is extremely high, since for each dollar raised by an increase in the access tax, $\$ 1.25$ of efficiency loss is created for the economy, beyond the tax revenue raised. Using $\$ 1.89$ billion of the $\$ 2.25$ billion of revenue per year for the Internet subsidy leads to an estimate of the efficiency loss to the U.S. economy of $\$ 2.36$ billion per year. ${ }^{28}$

When I calculate the marginal efficiency loss using the exact calculation based on equation (4) instead of the traditional approximation, I estimate it to be $\$ 1.250$, which is almost exactly the same as the estimate calculated from equation (6) of $\$ 1.249 .29$ Thus, for the marginal-efficiency-loss calculation the two methods lead to virtually identical results.

Three reasons exist for this high amount of marginal efficiency loss to the economy, which can be seen by an examination of equation (6): (1) the elasticity $\eta_{i}$ is relatively high, (2) $m_{i} / p_{i}$ is relatively low, since gross margins are high in long distance, which is to be expected given the large fixed costs of telecommunications networks, and (3) $t_{i} p_{i}$ is high, since a significant proportion of the subsidy to local service and contribution to the network's fixed and common costs comes from access charges on interstate long-distance service. To see how this efficiency loss compares with other taxes in the U.S. economy, I turn to a review of the literature.

\subsection{Previous Estimates of the Efficiency Loss from Taxation in the U.S. Economy}

Rather than taxing telecommunications use to fund the subsidy for Internet access for schools and libraries, Congress could have used general tax revenue. While no generally agreed-to value exists for the marginal

27 If, instead of the assumption that $\partial p_{i} / \partial t_{i}=1$, I use a differentiated product oligopoly markup model assumption along with constant elasticity demand curves, the marginal efficiency loss could be higher than 1.25 . Other oligopoly models, especially models based on linear demand curves, could find $\partial p_{i} / \partial t_{i}<1$. It is interesting to note that despite quite large price changes in long distance over the past 20 years, econometric estimates have found remarkably stable elasticity estimates.

${ }^{28}$ The $\$ 1.89$ billion is the amount that $I$ estimate will be raised from the tax on longdistance access; see footnote 10 for the calculation. The second term of equation (5) may well decrease over time due to the increased SLC on second lines to residences and the PICC (per customer charges) tax on long-distance companies. However, the decrease of the second term is unlikely to offset increases in the first term of equation (5) due to changes in technology. Furthermore, since the FCC intends to increase the tax revenue raised for universal service to almost $\$ 3$ billion, this term may well increase initially, compared to changes which would have otherwise occurred given the price-cap formula.

${ }^{29}$ In general no algebraic reason exists for the two estimates to be virtually identical, as happens in the current situation. 
TABLE 1

Marginal Efficiency Effects of Additional Taxes Raised ${ }^{31}$

\begin{tabular}{llc}
\hline Study & $\begin{array}{c}\text { Type } \\
\text { of taxes }\end{array}$ & $\begin{array}{c}\text { Marginal effect } \\
(\$)\end{array}$ \\
\hline Ballard, Shoven, and Whalley (1985) & U.S. & 0.365 \\
Browning (1987) & U.S. & 0.395 \\
Bovenberg and Goulder (1996) & U.S. & 0.260 \\
Hausman (1981b) & Income & 0.405 \\
\hline
\end{tabular}

efficiency loss to the economy from increasing overall taxes, the range of estimates is reasonably close. In Table 1 I present estimates of marginal effects of additional taxes. ${ }^{30}$

All of the estimates in Table 1 are below $\$ 0.405$ of marginal efficiency loss per dollar of additional revenue raised. Thus, they are all less than one-third of the efficiency loss created by the FCC when it increased the access rates on interstate long distance to fund the Internet subsidy for schools and libraries. Thus, the Congress and the FCC have used an extraordinarily expensive means to fund the Internet subsidy. ${ }^{31}$

\section{DID THE FCC MAXIMIZE THE EFFICIENCY LOSS?}

Given that taxes create economic distortions and lead to losses in producer surplus and consumer surplus, economic analysis leads to the recommendation that taxes should be chosen to minimize the efficiency loss effect on the economy. ${ }^{32}$ However, I believe the FCC chose the tax to fund the FCC Internet subsidy by the method which likely maximizes the loss in economic efficiency. Even if the tax chosen by the FCC did not absolutely maximize efficiency loss, it imposed extremely high unnecessary efficiency costs on the economy. I first demonstrate an alternative

30 Where a range of estimates is given in the original paper, I use the midpoint of the range. Feldstein (1995) has estimated significantly higher marginal efficiency losses from the income tax.

31 Since the government institutions for the income tax are in place, the incremental administrative cost for the Internet subsidy would be extremely small. The federal universal-service fund is going to finance a new government institution, the Universal Service Administrative Corporation, which will have significant fixed costs of operation. The FCC chose to establish this new administrative body, which will make the efficiency loss to the economy even greater than my calculations estimate it to be.

32 Of course, equity or distributional considerations also come into tax design. I discuss these considerations subsequently. 
method to raise the revenue for the Internet subsidy which leads to almost zero (or negative) loss in economic efficiency, and then discuss the policy options of the FCC.

\subsection{The Efficiency Effect of Increasing the Subscriber Line Charge}

The alternative method which the FCC could have used to raise the revenue for the Internet subsidy for schools and libraries is to increase the subscriber line charge (SLC). The SLC was established in 1984 and is a monthly fixed fee of $\$ 3.50$ per residential line and $\$ 6.00$ per business line. The FCC has not increased the SLC for residential households since 1984, despite about 50.5 percent inflation since that time. The SLC is used in large part to fund the joint and common costs of the local exchange carrier networks as well as the cross subsidy for local exchange access (e.g. local telephone service). Note that in terms of the efficiency effects on the economy the SLC is very attractive in that the own price elasticity of local access with respect to its price is estimated to be -0.005 by Hausman, Tardiff, and Belinfante (1993). ${ }^{33}$ Thus, the SLC acts similarly to a lump-sum tax, which has first best economic-efficiency properties, since it does not create an economic distortion; i.e., equation (3) is approximately zero, since $\eta$ is very near zero.

The FCC would have needed to increase the SLC by approximately $\$ 1.50$ per month to fund the Internet subsidy of $\$ 2.25$ billion per year. Note that this increase of $\$ 1.50$ is a little bit less than the amount of the inflation increase over the period 1984-1997, so that the increase would not quite have returned the SLC to its original value in real terms. ${ }^{34}$ Since social security and most other federal benefit programs for the needy are indexed, no increased hardship would have been created. ${ }^{35}$

To calculate the efficiency effects of this increase in the SLC, I return to

33 This estimate is for residential access. A one-standard-deviation change in the elasticity estimate would increase the magnitude to -0.007 , so that very similar conclusion would follow. While I am unaware of similar estimates for business lines, I would expect the elasticity to be similar or even lower. Since 14.7 percent of households had second lines in 1995, the elasticity for these could well be higher. However, given the higher income of residences with second lines, it is not necessarily true that the elasticity would be significantly higher. I am unaware of price elasticity estimates for these lines.

${ }^{34}$ For residential second lines the FCC did increase the SLC to $\$ 5.00$ and indexed the rate to inflation. However, second lines are a low percentage of overall residential lines, since only about 14.7 percent of residences have second lines.

${ }_{35}$ Numerous programs exist to subsidize telephone service for the needy. Besides a federal program, many states have additional programs. The details of the many programs and their overlap are too voluminous to be described here. 
equation (6) but now compute the marginal change in economic efficiency for a change in the SLC:

$$
\frac{\partial \Delta E}{\partial \mathrm{SLC}} \approx \frac{\eta_{j} \frac{1-m_{j}}{p_{j}}+\eta_{j} \frac{t_{j}}{p_{j}}+\left(\eta_{j} \frac{t_{j} m_{j}}{p_{j}^{2}}-0.5 \eta \frac{t_{j}^{2}}{p_{j}^{2}}\right) \frac{\partial p_{j}}{\partial \mathrm{SLC}}}{1-\eta_{j} \frac{t_{j}}{p_{j}} \frac{\partial p_{j}}{\partial \mathrm{SLC}}} .
$$

I first consider the second term in equation (7), which is the change in consumer surplus (after subtracting off tax revenue raised). Since the ratio $t_{j} / p_{j}=0.123$ for the SLC approximately, the marginal change in consumer surplus is about 0.0006 , using the assumption that $\partial p_{j} / \partial \mathrm{SLC}=$ $1 .{ }^{36}$ Thus, for each additional dollar of revenue raised, the efficiency loss is about $6 / 100$ of a penny, i.e. nearly zero, as expected.

Now the first term has a rather surprising outcome. Local access services for residential customers are priced below marginal (incremental) cost in most states as a policy to subsidize universal service, to subsidize rural customers, and to subsidize middle-class residential customers. The ratio of $m_{j} / p_{j}$ exceeds 1.0 , and a national average is approximately 1.25 . Thus, the first term equals -0.0013 , so that the sum of the initial two terms in the numerator of equation (7) yields a change in economic efficiency from increasing the SLC of -0.0007 , actually an increase in economic efficiency because the subsidy is decreased. When the last two terms in equation (7) are estimated and the denominator is computed, I calculate the marginal efficiency loss to be 0.0006 , or an efficiency loss of about $\$ 0.0006$ for each $\$ 1.00$ increase in the SLC. Thus, an increase in the SLC to fund the Internet subsidy has only an extremely small efficiency effect, essentially equal to zero. ${ }^{37}$

\subsection{Estimated Effects on Telephone Penetration from Increasing the SLC}

The FCC's stated rationale for increasing long-distance access charges to fund the Internet subsidy, rather than increasing the SLC, was that telephone penetration might decrease if the SLC were increased (First Report and Order in the Matter of Access Charge Reform, FCC 97-158,

36 This assumption holds true, since the price of local access is set by regulation.

${ }^{37}$ Even if the first term in equation (6) were set equal to zero, the marginal efficiency effect of an increase in the SLC would be over 1,000 times smaller than the policy that the FCC actually chose. 
May 7, 1997, para. 55). If the own price elasticity of -0.005 for local access is used, the estimated decrease in penetration would be a decrease in penetration of about -0.04 percent, or about 39,300 households. Even if the FCC is correct about decreased telephone penetration, its policy choice led to a loss in economic efficiency of $\$ 2.36$ billion per year or $\$ 60,050$ per year for each household that would have stopped subscribing to telephone service. Thus, the FCC policy choice led to an extremely expensive method to fund universal service. ${ }^{38}$ Expenditure of over $\$ 60,000$ per year per household to fund universal service could well raise questions about the policy choice.

However, it is not at all clear that the 39,300 households would have stopped subscribing to local service. As Hausman, Tardiff, and Belinfante (1993) discuss, households subscribe to telephone service to make both local and long-distance calls, as demonstrated in equation (1). Thus, an increase in the SLC, rather than an increase in long-distance access rate which leads to an increase in long-distance prices, can have a smaller effect or even a positive effect on telephone penetration. Here, longdistance access prices would have decreased because of the price-cap system used for regulation, and long-distance prices might also have decreased. ${ }^{39}$ The decrease in long-distance prices could well have more than offset the increase in local access prices caused by the increase in the SLC. Hausman, Tardiff, and Belinfante (1993) discuss how telephone penetration increased during 1984-1990, despite the inception of the $\$ 3.50$ payment increase in the SLC and other increases in local access rates, because of the decrease in long-distance prices. They calculate an increase in telephone penetration of 0.45 percent due to the inception of the SLC because the positive long-distance effect exceeded the negative SLC effect..$^{40}$ In the current situation I cannot estimate the overall effect on telephone penetration, because the oligopoly interaction of the longdistance companies does not permit an estimate of the expected decrease in long-distance prices. Nevertheless, the FCC's reasoning on the effect of telephone penetration from an increase in the SLC is unlikely to be correct.

38 Since econometric estimates have not found a significant externality effect from network externalities (e.g., Taylor [1994]), the $\$ 60,000$ spent per household leads to almost no aggregate benefits.

39 AT\&T promised the FCC that it would decrease its residential long-distance prices in 1997 when long-distance access prices decreased. Overall, the residential long-distance market has not been that competitive over the past five years.

40 During 1984-1990, AT\&T was regulated by the FCC and was generally required to pass on decreases in long-distance access charges through lower long-distance prices. 


\subsection{Other Possible Policy Choices of the FCC}

Given that the efficiency loss to the U.S. economy of raising $\$ 1.89$ billion per year by the FCC policy of an increased long-distance access tax is $\$ 2.36$ billion, are other policy options available to the FCC if it does not want to increase the SLC? One option would be to use a portion of the revenues that the FCC raises each year by auctioning off spectrum. During 1995-1996 the FCC auctioned off $120 \mathrm{MHz}$ of spectrum for use by PCS, which is digital cellular. Auction revenues exceeded $\$ 10$ billion. The FCC also auctioned off spectrum for specialized mobile radio (SMR) and has plans to auction at least another $120 \mathrm{MHz}$ (the ENG spectrum) in the next three years. The FCC could use a portion of these revenues to fund the Internet subsidy, and no adverse economic efficiency effects would be created, since the revenues bid are a form of pure profits tax levied on the buyers of the spectrum. ${ }^{41}$ Thus, use of government spectrum revenues to fund the Internet subsidy would have much lower efficiency costs to the U.S. economy than the policy chosen by the FCC.

Another possible policy to raise the revenue for the Internet subsidy is to charge Internet users the marginal cost of using the telephone network. During peak periods the marginal cost of Internet usage to the local telephone network is approximately $\$ 0.004-0.008$ per minute, whereas during off-peak periods the marginal cost is near zero. Currently, residential users of the Internet obtain free local service as part of their monthly service charge. Because of long holding periods of Internet usage on a telephone network designed for short voice calls, Internet usage has created service problems in a number of areas. Setting the price of Internet access equal to its marginal cost would decrease the distortions created by the current subsidy. ${ }^{42}$ However, it is unclear how much revenue a fee based on marginal cost would generate, and it might be significantly less than $\$ 2.25$ billion per year.

Neither of these policies would create a loss of economic efficiency. Indeed, the latter policy of charging Internet users their marginal cost could actually lead to an increase in economic efficiency. Similarly, the use of an increase in the SLC of approximately $\$ 1.50$ per month would lead to at most an extremely small loss in economic efficiency and could well lead to a gain in economic efficiency. Furthermore, the FCC's pro-

41 Indeed, proponents of a Henry George approach to taxation should realize that the value of the electromagnetic spectrum could be an important addition to property-based taxation.

42 While long-distance users pay the SLC and per-minute long-distance access charges, Internet users pay no fee because of an exemption granted by the FCC in 1988. Internet users have become a very powerful lobby, through bulletin boards and e-mail, to retain the subsidy they receive. 
fessed concern for possible effects on telephone penetration is likely incorrect. Even if correct, the cost to the economy would be approximately $\$ 60,000$ per household per year to keep them on the telephone network. Thus, the FCC chose an extremely high efficiency cost means to raise the revenue for the Internet subsidy-the FCC likely maximized the efficiency loss (deadweight loss) to the economy, rather than minimizing the economic efficiency loss. The FCC's policy choice will cost the economy at least $\$ 2.36$ billion per year.

\section{CONCLUSIONS}

The FCC controls one of the most important and dynamic industries in the U.S. economy. However, many FCC policy choices have been made without regard to economic considerations. For instance, in my previous research I have demonstrated that FCC policy with respect to cellular telephones cost consumers and the economy over $\$ 100$ billion. Current FCC policy towards long-distance competition is likely costing consumers about $\$ 7$ billion per year. These large amounts of consumer harm are significant, even in relation to efficiency considerations raised by general U.S. tax policy.

In this paper I consider the efficiency effect of recent FCC policy to raise $\$ 2.25$ billion per year to fund an Internet subsidy to schools and libraries. I estimate that the efficiency loss is about $\$ 1.25$ per dollar raised, or a total of $\$ 2.36$ billion per year on the $\$ 1.89$ billion per year raised through the increase in the long-distance access tax. The FCC could have raised this same amount of revenue with little or no loss in economic efficiency by increasing the subscriber line charge. The increase in the SLC would have returned it to its initial real value when the SLC was begun in 1984. FCC policy here had the opposite effect to that which arises from economic analysis: the FCC chose the policy which likely maximizes the efficiency loss to the economy, rather than minimizing it. Since regulation of the telecommunications network in the U.S. is a grab bag of taxes and subsidies, the FCC needs to begin to pay attention to the efficiency effects of its regulatory policy. Otherwise, it will continue to cost consumers and the economy billions of dollars per year because of regulatory policy that creates quite large efficiency losses to the U.S. economy.

\section{REFERENCES}

Auerbach, A. (1985). "The Theory of Excess Burden and Optimal Taxation." In Handbook of Public Economics, A. Auerbach and M. Feldstein (eds.). Amsterdam: North Holland. 
Ballard, C., J. Shoven and J. Whalley (1995). "General Equilibrium Computations of the Marginal Welfare Costs of Taxes in the United States." American Economic Review March: 128-138.

Bovenberg, L. A., and L. Goulder (1996). "Optimal Environmental Taxation in the Presence of Other Taxes: General - Equilibrium Analyses." American Economic Review 86: 985-1000.

Browning, E. (1987). "On the Marginal Welfare Cost of Taxation." American Economic Review March: 11-23.

Diamond, P. and J. Mirrlees (1971). "Optimal Taxation and Public Production." American Economic Review 61.

Eriksson, R., D. Kaserman, and J. Mayo (1995). "Targeted and Untargeted Subsidy Schemes; Evidence from Post-divestiture Efforts to Promote Universal Telephone Service." Department of Economics, University of Tennessee. October.

Feldstein, M. (1995). "Tax Avoidance and the Deadweight Loss of the Income Tax." NBER Working Paper no. 5055.

Gatto, J., et al. (1988). "Interstate Switched Access Demand." Information Economics and Policy 3.

Hausman, J. (1981a). "Exact Consumer's Surplus and Deadweight Loss." American Economic Review 71.

(1981b). "Income and Payroll Tax Policy and Labor Supply." In The Supply Side Effects of Economic Policy, L. Meyer (ed.). St. Louis: Federal Reserve. (1995). "Proliferation of Networks in Telecommunications: Technological and Economic Considerations." In Networks, Infrastructure, and the New Task for Regulation, D. Alexander and W. Sichel (eds.). University of Michigan Press. (1997). "Valuation and the Effect of Regulation on New Services in Telecommunications." Forthcoming in Brookings Papers on Economic Activity, Microeconomics.

, T. Tardiff, and A. Belinfante (1993). "The Effects of the Breakup of AT\&T on Telephone Penetration in the United States." American Economic Review 83.

Kahn, A.E. (1988). The Economics of Regulation. Cambridge University Press.

Laffont, J.J., and J. Tirole (1996). "Competition in Telecommunications." University of Toulouse. November. Mimeo.

Perl, L. (1984). "A New Study of Economic and Demographic Determinants of Residential Demand for Basic Telephone Service." National Economic Research Associates. Mimeo.

Posner, R. (1971). "Taxation by Regulation." Bell Journal of Economics 2:22-50.

Poterba, J. (1997). "Do Budget Rules Work?" In Fiscal Policy: Lessons From Economic Research, A. Auerbach (ed.). Cambridge, MA: MIT Press.

Solvason, D. (1997). "Cross-Sectional Analysis of Residential Telephone Subscription in Canada Using 1994 Data." Information Economics and Policy 9:241264.

Taylor, L. D. (1994). Telecommunications Demand in Theory and Practice. Boston: Kluwer Academic Publishers.

Taylor, W., and L. Taylor, (1993). "Post-divestiture Long- Distance Competition in the United States." American Economic Review 83. 